\title{
New insights into the pathogenesis of pseudoxanthoma elasticum and related soft tissue calcification disorders by identifying genetic interactions and modifiers
}

\section{Doris Hendig*, Cornelius Knabbe and Christian Götting}

Institut für Laboratoriums- und Transfusionsmedizin, Herz- und Diabeteszentrum Nordrhein-Westfalen, Universitätsklinik der Ruhr-Universität Bochum, Bad Oeynhausen, Germany

\section{Edited by:}

Olivier M. Vanakker, Ghent University

Hospital, Belgium

\section{Reviewed by:}

Chi Zhang, University of

Nebraska-Lincoln, USA

Alexey Goltsov, University of Abertay

Dundee, UK

\section{${ }^{*}$ Correspondence:}

Doris Hendig, Institut für Laboratoriums- und

Transfusionsmedizin, Herz- und

Diabeteszentrum

Nordrhein-Westfalen,

Universitätsklinik der Ruhr-Universität

Bochum, Georgstraße 11, 32545 Bad

Oeynhausen, Germany

e-mail: dhendig@hdz-nrw.de
Screening of the adenosine triphosphate binding cassette transporter protein subfamily $\mathrm{C}$ member 6 gene (ABCC6) in pseudoxanthoma elasticum (PXE) revealed a mutation detection rate of approximately $87 \%$. Although $25 \%$ of the unidentified disease alleles underlie deletions/insertions, there remain several PXE patients with no clear genotype. The recent identification of PXE-related diseases and the high intra-familiar and inter-individual clinical variability of PXE led to the assumption that secondary genetic co-factors exist. Here, we summarize current knowledge of the genetics underlying PXE and PXE-related disorders based on human and animal studies. Furthermore, we discuss the role of genetic interactions and modifier genes in PXE and PXE-related diseases characterized by soft tissue calcification.

\section{Keywords: PXE, rare disease, mineralization, calcification, genetic interaction, genetic modifier}

\section{INTRODUCTION}

Mutations in $A B C C 6$, a gene encoding for the $\mathrm{ABC}$ transporter protein 6 of subfamily C, formerly known as multidrug resistanceassociated protein 6 (MRP6), are the cause of pseudoxanthoma elasticum (PXE; Kool et al., 1999; Bergen et al., 2000; Le Saux et al., 2000; Ringpfeil et al., 2000; Miksch et al., 2005; Schulz et al., 2006). PXE is an autosomal recessive disorder characterized by soft tissue calcification primarily in the skin, Bruch's membrane in the retina and the vessel walls (Neldner and Struk, 2002). To date, more than 300 - mostly unique - PXE-associated ABCC6 mutations have been identified \{http://www.ncbi.nlm.nih.gov/lovd/home.php? select_db=ABCC6\}. Despite large epidemiological studies including more than 500 well-characterized PXE patients, no genotypephenotype correlations have been discovered so far. Moreover, there is a great clinical variability between PXE patients, even within families with more than one person affected. This heterogeneity between patients raised the question of whether factors, e.g., environmental or genetic background, contribute to PXE manifestation, disease progression, and severity. The assumption is supported by the description of PXE-related diseases (Vanakker et al., 2007) as well as clinical overlaps with other rare monogenic syndromes and common cardiovascular disorders (Trip et al., 2002). A recent publication in this special issue on soft tissue mineralization focused on the clinical phenotype of PXE and its parallels to other cardiovascular diseases (Lefthériotis et al., 2013). Here, we summarize the role of $A B C C 6$ mutations as cause of PXE, and discuss the current knowledge of genetic cofactors (modifiers) and genetic interactions for PXE and related disorders.

\section{MUTATIONAL ANALYSIS OF THE ABCC6 GENE}

Recently, the PXE candidate gene, ABCC6 (MIM \#603234), was identified and mutations in this gene were found to cause PXE (exemplarily: Le Saux et al., 2000). The ABCC6 gene contains 31 exons and encodes a $165 \mathrm{kDa}$ transmembrane transporter of 1503 amino acids. The physiological function of ABCC6 is still unknown. To date, more than 300 causative ABCC6 mutations have been identified. These include missense, nonsense, and splice site mutations, as well as deletions and insertions. According to current studies, PXE seems to be inherited in an exclusively autosomal recessive mode (Plomp et al., 2004; Miksch et al., 2005; Pfendner et al., 2007). Hence, PXE patients are homozygous or compound heterozygous carriers of $A B C C 6$ mutations. Most mutations observed in $A B C C 6$ are unique and the majority of them are located within cytoplasmic domains of ABCC6. The most frequent mutation found in PXE patients is a nonsense mutation in exon 24, p.R1141X (c.3421C > T, rs72653706), which is found in approximately $25 \%$ of the European patient population. A larger deletion of exons 23-29 (c.2996_4208del) represents the most common mutation (25\%) in American PXE patients. The mutation detection rate lies between 80 and 90\%. Consequently, in up to $20 \%$ of patients clinically diagnosed with PXE, only one or no $A B C C 6$ mutations were detected. As a consequence of methodological limitations, small $A B C C 6$ deletions/insertions in homozygous state could be missed by direct sequencing approaches. Costrop et al. (2010) uncovered about $25 \%$ of the missing alleles as deletions of various sizes by performing multiplex ligation-dependent probe amplification (MLPA). These findings emphasize the importance of screening 
for deletion/insertions in the molecular diagnostics of PXE. Nevertheless, there still remain PXE patients with an incomplete ABCC6 genotype. Consequently, other genetic causes or environmental factors may be involved in PXE manifestation.

\section{GENETIC INTERACTIONS}

The recent identification of inherited disorders related to PXE and characterized by soft tissue calcification suggests multiple genetic factors. Vanakker et al. (2007) described a novel PXE-like syndrome (MIM \#610842), which is inherited in an autosomal recessive mode, but caused by mutations in the GGCX gene, encoding $\gamma$-glutamate carboxylase. Patients present with generalized redundant skin folds, a mild retinopathy and a coagulation defect of vitamin K-dependent clotting factors (Vanakker et al., 2007). Similar cases had already been reported in the early 1990 s (Le Corvaisier-Pieto et al., 1996). Histological examination of a skin biopsy reveals fragmentation and calcification of mid-dermal elastic fibers identical to PXE. However, ultrastructural analysis by electron microscopy showed differences in elastic fiber mineralization: in PXE-like syndrome, the calcification occurred in the periphery of the elastic fiber rather than in the fiber core. $\mathrm{Li}$ et al. (2009a,b) described two different families with combined features of PXE and a vitamin K-dependent coagulation deficiency. In both studies mutational screening of ABCC6, GGCX, and VKORC1 revealed two putative pathogenic mutations in $G G C X$ in patients presenting with distinct skin lesions and a coagulation factor deficiency. Interestingly, the authors observed similar skin lesions in the mother and her twin sister with no evidence of a coagulation disorder (Li et al., 2009a). Mother and maternal aunt were identified as compound heterozygous carriers of the recurrent ABCC6 nonsense mutation p.R1141X and a missense mutation in GGCX (p.S300F). The authors suggested that the skin phenotype is because of digenic inheritance.

Generalized arterial calcification of infancy (GACI, MIM \#208000) is another rare autosomal recessive trait characterized by soft tissue calcification (Rutsch et al., 2003). Mutations in ENPP1, encoding for ectonucleotide pyrophosphatase 1, are the primary cause of GACI. Patients present with extensive hydroxyapatite deposition in large and medium-sized arteries, leading to arterial stenosis and visceral ischemia. A recent study reported on a family with two brothers (Le Boulanger et al., 2010). One was suffering from PXE, while the other died at 15 months of age from a condition similar to GACI. Molecular analysis of ABCC6 and ENPP1 in this family revealed two pathogenic ABCC6 mutations in heterozygous state as the primary cause of disease. Pathogenic ENPP1 mutations were not identified except for two common ENPP1 sequence variations. It remains speculative whether these lead to a more severe disease progression. Following on from these results, Nitschke et al. (2012) screened ABCC6 and reanalyzed ENPP1 for pathogenic mutations in a larger cohort of patients with clinically proven GACI $(n=92)$. The authors found 30 patients who did not carry any ENPP1 mutations. Pathogenic ABCC6 mutations in homo- or compound-heterozygosity were found as the primary cause for GACI in 15 patients (Nitschke et al., 2012). The fact that mutations in ENPP1 and ABCC6 manifest in overlapping clinical phenotypes of GACI and PXE suggests similar metabolic pathways are involved in the pathogenesis.
The significance of genetic interactions is further supported by experimental studies with $A b c c 6^{-/-} ; G g c x^{+/+}$mice in which the onset of ectopic calcification was delayed, whereas $A b c c 6^{-/-} ; G g c x^{-/+}$mice presented with accelerated mineralization (Li and Uitto, 2010).

\section{GENETIC MODIFIERS OF PXE}

The variability in the outcome and progression of PXE may include variations in several of the functional pathways involved in the pathophysiology of the disease in addition to the loss of ABCC6 function. Detection of such "modifier genes" may uncover major pathways involved in the pathogenesis and provide targets for therapeutic intervention. Studies with $A b c c 6^{-/-}$mice support the hypothesis of the contribution of other genetic factors in PXE-related calcification since these mice present with different phenotypes (Gorgels et al., 2005; Klement et al., 2005).

\section{DEFINITION OF MODIFIER GENES}

The "genetic co-factor" concept is not new, and was introduced by Haldane as early as 1941 (Haldane, 1941). A primary reason for searching for genetic factors modifying disease is to provide information on the disease course and to improve therapies (if available). Several definitions of so-called "modifier genes" exist in the literature. We define a modifier gene as a gene that if "mutated," is insufficient on its own to cause disease, but when coupled with another genetic mutation, produces or enhances its pathogenesis. "Modifier genes" have been detected for cystic fibrosis, another monogenic disorder caused by an ABCC transporter defect ( $A B C C 7$ gene) with variable disease onset and progression (Cutting, 2005; Drumm et al., 2005).

\section{SELECTION OF CANDIDATE GENES}

In PXE several metabolic pathways seem to be affected, e.g., the regulation of biological calcification, extracellular matrix (ECM) remodeling and lipid transport and biosynthesis. Sequence variations in genes regulating these pathways may be involved in the development and clinical course of PXE.

\section{Regulation of biological calcification}

Ectopic calcification is the result of a complex interplay between stimulating and inhibitory proteins and metabolites. One candidate gene for PXE susceptibility is secreted phosphoprotein 1 (SPP1, formerly known as osteopontin). SPP1 fulfils important functions in the regulation of biological calcification and was also found to be a constitutive component of elastic fibers in order to prevent them from calcification (Baccarani-Contri et al., 1994). A study by Aherrahrou et al. described a dramatic up-regulation of SPP1 expression in mice suffering from dystrophic cardiac calcification (DCC, Aherrahrou et al., 2004). The $A b c c 6$ gene was identified as the potential candidate gene for DCC in mice (Korff et al., 2006). SPP1 is a predominantly transcriptional regulated gene and the SPP1 promoter is highly conserved among the human, murine, and porcine genes (Hijiya et al., 1994). Several polymorphisms in SPP1 were shown to affect SPP1 expression (Giacopelli et al., 2004; D'Alfonso et al., 2005; Hummelshoj et al., 2006). We found that the c.-1748G, the c.155_156insG and the c.244_245insTG alleles appear to be significantly more common in PXE patients (Hendig et al., 2007). The polymorphism 
c.-155_156insG generates a RUNX2 (runt-related transcription factor 2) binding site closed to a second RUNX2 binding site in the $S P P 1$ promoter. RUNX2 is an essential transcriptional regulator of osteoblast differentiation and bone formation. Conclusively, we interpreted three SPP1 promoter polymorphisms and the haplotype combining these disease-associated alleles as a putative genetic risk pattern for PXE.

Fetuin-A, was found to be a major systemic inhibitor of calcification (Jahnen-Dechent et al., 2001). Carriers of fetuin-A genotype 2 have been shown to have the lowest serum fetuin-A concentration (Stenvinkel et al., 2005). Even though we did not observe an association between PXE manifestation and fetuin-A genotype, it could be speculated that fetuin-A genotype 2 is an additional disease-promoting risk factor (Hendig et al., 2006).

Matrix gla protein (MGP) is a calcification inhibitor acting locally. MGP was also found in the circulatory system, where it is part of the so-called calciprotein particles, together with fetuin-A and hydroxyapatite. The importance of MGP in preventing pathological calcification is supported by Mgp-deficient mice, which develop severe arterial calcification (Munroe et al., 1999). Analysis of the MGP promoter polymorphism frequencies revealed one MGP haplotype to be a potential protective genetic co-factor in PXE (Hendig et al., 2008).

\section{ECM-remodeling and oxidative stress}

Several studies reported an increased ECM remodeling in skin of PXE patients. In this context increased expression of proteases, a mild oxidative stress, and an altered proteoglycan metabolism was detected. The latter resulted in increased accumulation of proteoglycans in the ECM, and in changes in the structure and composition of urinary glycosaminoglycans (Longas et al., 1986; Maccari et al., 2003; Kornet et al., 2004; Volpi and Maccari, 2005).

Many of the alterations observed in PXE could be explained by oxidative stress, for instance ECM remodeling. We found a correlation between genotype and age of disease onset for polymorphisms in the genes catalase (CAT, c.262C > T), superoxide dismutase 2 (SOD2, c.47C $>\mathrm{T})$, and glutathione peroxidase 1 (GPX1, c.593C > T), encoding essential antioxidant enzymes (Zarbock et al., 2007). Furthermore, the age of disease onset was inversely correlated with the number of mutated alleles, indicating a cumulative effect on the time of PXE onset.

Elevated production of MMP2 (matrix metallopeptidase 2) in PXE fibroblasts and increased levels of MMP2 and MMP9 in serum from PXE patients were shown (Quaglino et al., 2005; Diekmann et al., 2009). Increased MMP expression may at least partly result from genetic variation. We have previously shown that variations in MMP2 are a genetic co-factor for PXE (Zarbock et al., 2010).

We propose that xylosyltransferase I (XYLT, XT-I), as the initial and most important enzyme in proteoglycan biosynthesis, and XT-II, as a highly homologous protein, might contribute to the increased ECM synthesis rate in PXE. As most XT-I is secreted into the ECM, XT activity was proposed as a diagnostic marker for the determination of enhanced proteoglycan biosynthesis and tissue destruction (Götting et al., 2007). Moreover, elevated XT activity was found in sera from PXE patients, reflecting the higher proteoglycan biosynthesis rate (Götting et al., 2005). We further showed that three sequence variants in the XYLT2 gene result in a severe disease course of PXE (Schön et al., 2006).

\section{Angiogenesis}

Choroidal neovascularization (CNV) in PXE-associated retinopathy is believed to be mediated by the action of vascular endothelial growth factor (VEGF). Intravitreal anti-VEGF therapy with ranibizumab or bevacizumab is beneficial for the treatment of CNV secondary to angioid streaks associated with PXE (Gliem et al., 2013). It seems justified to assume that polymorphisms leading to altered VEGF expression may modify the severity of PXE retinopathy. Five VEGFA sequence variants showed significant association with severe retinopathy in PXE (Zarbock et al., 2009). We identified the most significant association for the variant c. $-460 \mathrm{C}>\mathrm{T}$ with an Odds Ratio of 3.8 (95\% confidence interval 2.0-7.3, $P_{\text {corrected }}$ 0.0003). VEGFA gene polymorphisms might prove useful as a prognostic marker for development of PXEassociated retinopathy leading to earlier therapeutic intervention in order to prevent loss of central vision.

\section{Lipid biosynthesis and metabolism}

About $50 \%$ in the general population present with dyslipidemia which is a high risk factor for coronary artery disease (CAD). Familial hypercholesterolemia is caused by genetic variations in different genes, including low density lipoprotein receptor $(L D L R)$ and the apolipoprotein $\mathrm{B}(A P O B)$. Heterozygous carriers are found with a frequency of 1 in 500. Dyslipidemia is likewise observed in PXE patients and case reports suggested an impact of genetic risk factors of lipid metabolism (LDLR mutations), for severe complications such as stroke in PXE (Pisciotta et al., 2010).

\section{GENETIC MODIFIERS IN Abcc6 DEFICIENT MOUSE STRAINS}

Genetic examination of nine different mice strains predisposed to more or less severe soft tissue calcification reveal a common Abcc6 sequence variant in exon 14 as the primary trigger in four of them (c.1866G>A, p.R621C, rs32756904). All these mice strains are prone to soft tissue calcification, but present with immense phenotypic heterogeneity. However, no modifier genes have been identified so far, even though not the correct candidate genes (Ssp1 instead of Spp1) were evaluated in a recent study (Berndt et al., 2012). Whole genome screening and careful evaluation of putative candidate genes will shed light on the role of genetic factors contributing to soft tissue calcification caused by Abcc6 deficiency. It will be of high interest to gain a deeper insight into the genetic background of these mice strains.

\section{ABCC6 VARIANTS AS GENETIC MODIFIER OF OTHER RARE AND COMMON DISEASES}

The occurrence of a mild skin phenotype was previously reported in heterozygous carriers of ABCC6 mutations, although the findings could not be replicated in another study (Martin et al., 2007, 2008; Plomp et al., 2009). By searching for biomarkers in biological fluids of PXE patients, we and others observed that unaffected first-degree relatives mostly display results, e.g., for serum fetuinA, desmosine, that were different from normal and intermediate between that of the PXE patients and the controls (Annovazzi et al., 2004; Hendig et al., 2006). Most of these individuals had 
been identified as heterozygous carriers of only one ABCC6 mutation. Taken together, these results underline the assumption that ABCC6 mutations on a single allele might determine a mild PXE phenotype. This hypothesis might have great impact considering ABCC6 as genetic modifier of other rare monogenic disorders (GACI), or common disease (stroke, myocardial infarction, and CAD). Wang et al. (2001) reported an association of the frequent ABCC6 p.R1268Q variant (c.3803G >A, rs2238472) with plasma triglyceride and low HDL (high-density lipoprotein) cholesterol. Peloso et al. (2010) replicated these data by identification of an $A B C C 6$ sequence variant ( $r s 150468$; c.3736-334A $>C$ ) as a susceptibility allele for low HDL cholesterol. Both studies led to the suggestion that ABCC6 may be an important determinant of plasma lipoproteins.

Few studies investigated the correlation of ABCC6 mutations with cardiovascular disease and identified the frequent mutation p.R1141X as a strong genetic risk factor for CAD (Trip et al., 2002; Wegman et al., 2005; Köblös et al., 2010). However, a large Danish Study including more than 13,600 cases, presenting with ischemic vascular disease, could not replicate this findings (Hornstrup et al., 2011). In conclusion, the impact of ABCC6 variants as a genetic risk factor for common cardiovascular diseases remains to be elucidated.

\section{LIMITATIONS AND PERSPECTIVE}

Monogenic diseases such as PXE and GACI represent simple models that teach us many things about the genetic basis of more complex disorders, e.g., arterial calcification (Antonarakis and Beckmann, 2006). Considerable variety in the clinical expression of a monogenic disease might be explained by the effect of other genetic factors that modify the expression of the disease phenotype. Many arguments support the concept of modifier genes and genetic interactions. We suggest that genetic interactions, as one example between $A B C C 6$ and ENPP1, point toward new disease entities which seem to be phenotypically similar to PXE or GACI at first sight but differ in yet unknown features. Genetic modifiers are discussed as concomitant factors contributing to the course of the

\section{REFERENCES}

Aherrahrou, Z., Axtner, S. B., Kaczmarek, P. M., Jurat, A., Korff, S., Doehring, L. C., et al. (2004). A locus on chromosome 7 determines dramatic up-regulation of osteopontin in dystrophic cardiac calcification in mice. Am. J. Pathol. 164, 13791387. doi: 10.1016/S0002-9440(10) 63224-5

Annovazzi, L., Viglio, S., Gheduzzi, D., Pasquali-Ronchetti, I., Zanone, C., Cetta, G., et al. (2004). High levels of desmosines in urine and plasma of patients with pseudoxanthoma elasticum. Eur. J. Clin. Invest. 34, 156164. doi: 10.1111/j.1365-2362.2004. 01306.x

Antonarakis, S. E., and Beckmann, J. S. (2006). Mendelian disorders deserve more attention. Nat. Rev. Genet. 7, 277-282. doi: 10.1038/nrg 1826
Baccarani-Contri, M., Vincenzi, D., Cicchetti, F., Mori, G., and Pasquali-Ronchetti, I. (1994). Immunochemical identification dermis of pseudoxanthoma elasticum patients. Eur. J. Histochem. 38, 111-123.

Bergen, A. A., Plomp, A. S., Schuurman, E. J., Terry, S., Breuning, M., Dauwerse, H., et al. (2000). Mutations in ABCC6 cause pseudoxanthoma elasticum. Nat. Genet. 25, 228-231. doi: 10.1038/76109 Y., Silva, K. A., Kennedy, V., et al. (2012). A single-nucleotide polymorphism in the Abcc6 gene associates with connective tissue mineralization in mice similar to targeted models for pseudoxanthoma elasticum. J. Invest. Dermatol. 133, 833-836. doi: 10.1038/jid.2012.340 of abnormal constituents in the

Berndt, A., Li, Q., Potter, C. S., Liang,

disease. The search for modifier genes is difficult but worth being performed in view of better knowledge of biological pathways affected by the disease. Moreover, numerous studies have identified such genes in mice. The availability of various mouse strains carrying the same $A b c c 6$ sequence variation associated with more or less severe soft tissue calcification provides an excellent starting point for functional studies and the investigation of interactions between ABCC6 and specific modifier genes (Berndt et al., 2012). The recent identification of modifier genes for PXE underscores the importance of the analysis of gene-gene environment interactions in understanding the development of complex phenotypes such as PXE. As genetic modifiers are known to alter the course and expression of disease, their gene products become interesting targets for therapeutic intervention. Discovery of genetic modifiers for example affecting the success of anti-neovascular therapy could be, in the future, a key issue to obtain a personalization of therapy and to avoid unnecessary costs in PXE. Nevertheless, replication studies analyzing the new association of modifier genes in other PXE patient cohorts are essential to determine whether these modifier genes are indeed a genetic risk factor for PXE and related disorders. Moreover, the importance of consistent phenotype measures and complementary study designs cannot be overemphasized. Here, family studies and sibling analysis may help to estimate the contribution of genetic and non-genetic factors.

\section{ACKNOWLEDGMENTS}

We are very grateful to all the PXE patients and their relatives, whose cooperation made our studies possible. Furthermore, we would like to thank Peter Hof, chairman of the Selbsthilfegruppe für PXE Erkrankte Deutschlands e.V., the clinical ambulance for PXE at the Bethesda hospital in Freudenberg, Germany and the University Eye Hospital in Bonn, Germany. This work was supported by grants from the "Deutsche Forschungsgemeinschaft" (DFG He 5900/2-1) and the Rectorate of the Ruhr-Universität Bochum. We further thank Sarah L. Kirkby for her linguistic advice.

Costrop, L. M., Vanakker, O. O. Van Laer, L., Le Saux, O., Martin, L., Chassaing, N., et al. (2010). Novel deletions causing pseudoxanthoma elasticum underscore the genomic instability of the ABCC6 region. J. Hum. Genet. 55, 112-117. doi: 10.1038/jhg.2009. 132

Cutting, G. R. (2005). Modifier genetics: cystic fibrosis. Annu. Rev. Genomics Hum. Genet. 6, 237-260. doi: 10.1146/annurev.genom.6.080604. 162254

D’Alfonso, S., Barizzone, N., Giordano, M., Chiocchetti, A., Magnani, C., Castelli, L., et al. (2005). Two single-nucleotide polymorphisms in the $5^{\prime}$ and $3^{\prime}$ ends of the osteopontin gene contribute to susceptibility to systemic lupus erythematosus. Arthritis Rheum. 52, 539-547. doi: 10.1002/art. 20808
Diekmann, U., Zarbock, R., Hendig, D., Szliska, C., Kleesiek, K., and Götting, C. (2009). Elevated circulating levels of matrix metalloproteinases MMP2 and MMP-9 in pseudoxanthoma elasticum patients. J. Mol. Med. 87, 965-970. doi: 10.1007/s00109-0090497-5.

Drumm, M. L., Konstan, M. D., Schluchter, A., Handler, R., Pace, R., Zou, F., et al. (2005). Genetic modifiers of lung disease in cystic fibrosis. N. Engl. J. Med. 34, 355-363.

Giacopelli, F., Marciano, R., Pistorio, A., Catarsi, P., Canini, S., Karsenty, G., et al. (2004). Polymorphisms in the osteopontin promoter affect its transcriptional activity. Physiol. Genomics 20, 87-96. doi: 10.1152/physiolgenomics.00138.2004

Gliem, M., Zaeytijd, J. D., Finger, R. P., Holz, F. G., Leroy, B. P., Charbel Issa, P. (2013). An update on the ocular 
phenotype in patients with pseudoxanthoma elasticum. Front. Genet. 4:14. doi: 10.3389/fgene.2013.00014 Gorgels, T. G., Hu, X., Scheffer, G. L., Van Der Wal, A. C., Toonstra, J., De Jong, P. T., et al. (2005). Disruption of Abcc6 in the mouse: novel insight in the pathogenesis of pseudoxanthoma elasticum. Hum. Mol. Genet. 14, 1763-1773. doi: 10.1093/hmg/ddil 83

Götting, C., Hendig, D., Adam, A., Schön, S., Schulz, V., Szliska, C., et al. (2005). Elevated xylosyltransferase I activities in pseudoxanthoma elasticum (PXE) patients as a marker of stimulated proteoglycan biosynthesis. J. Mol. Med. 83, 984-992.

Götting, C., Kuhn, J., and Kleesiek, K. (2007). Human xylosyltransferases in health and disease. Cell. Mol. Life Sci. 64, 1498-1517.

Haldane, J. B. (1941). The relative importance of principal and modifying genes in determining some human diseases. J. Genet. 41, 149 157. doi: 10.1007/BF02983018

Hendig, D., Arndt, M., Szliska, C., Kleesiek, K., and Götting, C. (2007). SPP1 promoter polymorphisms: identification of the first modifier gene for pseudoxanthoma elasticum. Clin. Chem. 53, 829-836.

Hendig, D., Schulz, V., Arndt, M., Szliska, C., Kleesiek, K., and Götting, C. (2006). Role of serum fetuin-A, a major inhibitor of systemic calcification, in pseudoxanthoma elasticum. Clin. Chem. 52, 227-234.

Hendig, D., Zarbock, R., Szliska, C., Kleesiek, K., and Götting, C. (2008). The local calcification inhibitor matrix Gla protein in pseudoxanthoma elasticum. Clin. Biochem. 41, 407-412. doi: 10.1016/ j.clinbiochem.2007.12.023

Hijiya, N., Setoguchi, M., Matsuura, K., Higuchi, Y., Akizuki, S., and Yamamoto, S. (1994). Cloning and characterization of the human osteopontin gene and its promoter. Biochem. J. 303( $\mathrm{Pt} \mathrm{1})$, 255-262.

Hornstrup, L. S., Tybjaerg-Hansen, A., Haase, C. L., Nordestgaard, B. G., Sillesen, H., Grande, P., et al. (2011). Heterozygosity for R1141X in ABCC6 and risk of ischemic vascular disease. Circ. Cardiovasc. Genet. 4, 534-541. doi: 10.1161/CIRCGENETICS.110.958801

Hummelshoj, T., Ryder, L. P., Madsen, H. O., Odum, N., and Svejgaard, A. (2006). A functional polymorphism in the Eta- 1 promoter is associated with allele specific binding to the transcription factor Sp1 and elevated gene expression. Mol.
Immunol. 43, 980-986. doi: 10.1016/ j.molimm.2005.05.012

Jahnen-Dechent, W., Schäfer, C., Heiss, A., and Grötzinger, J. (2001). Systemic inhibition of spontaneous calcification by the serum protein alpha 2-HS glycoprotein/fetuin. Z. Kardiol. 90(Suppl. 3), 47-56.

Klement, J. F., Matsuzaki, Y., Jiang, Q. J., Terlizzi, J., Choi, H. Y., Fujimoto, N., et al. (2005). Targeted ablation of the abcc6 gene results in ectopic mineralization of connective tissues. Mol. Cell Biol. 25, 8299-8310. doi: 10.1128/MCB.25.18.8299-8310. 2005

Köblös, G., Andrikovics, H., Prohaszka, Z., Tordai, A., Varadi, A., and Aranyi, T. (2010). The R1141X lossof-function mutation of the ABCC6 gene is a strong genetic risk factor for coronary artery disease. Genet. Test. Mol. Biomarkers 14, 75-78. doi: 10.1089/gtmb.2009.0094

Kool, M., Van Der Linden, M., De Haas, M., Baas, F., and Borst, P. (1999). Expression of human MRP6, a homologue of the multidrug resistance protein gene MRP1, in tissues and cancer cells. Cancer Res. 59, 175-182.

Korff, S., Schoensiegel, F., Riechert, N., Weichenhan, D., Katus, H. A., and Ivandic, B. T. (2006). Fine mapping of Dyscalc1, the major genetic determinant of dystrophic cardiac calcification in mice. Physiol. Genomics 25, 387-392. doi: 10.1152/physiolgenomics.00010.2006

Kornet, L., Bergen, A. A., Hoeks, A. P. Cleutjens, J. P., Oostra, R. J., Daemen, M. J., et al. (2004). In patients with pseudoxanthoma elasticum a thicker and more elastic carotid artery is associated with elastin fragmentation and proteoglycans accumulation. Ultrasound Med. Biol. 30, 1041-1048. doi: 10.1016/j.ultrasmedbio.2004 06.004

Le Boulanger, G., Labrèze, C., Croué, A. Schurgers, L. J., Chassaing, N., Wittkampf, T., et al. (2010). An unusual severe vascular case of pseudoxanthoma elasticum presenting as generalized arterial calcification of infancy. Am. J. Med. Genet. A 152A, 118-23. doi: 10.1002/ajmg.a.33162.

Le Corvaisier-Pieto, C., Joly, P. Thomine, E., Lair, G., and Lauret, P. (1996). [Generalized pseudoxanthoma elasticum combined with vitamin $\mathrm{K}$ dependent clotting factors deficiency]. Ann. Dermatol. Venereol. 123, 555-558.

Lefthériotis, G., Omarjee, L., Le Saux, O., Henrion, D., Abraham, P., Prunier, F., etal. (2013). The vascular phenotype in pseudoxanthoma elasticum and related disorders: contribution of a genetic disease to the understanding of vascular calcification. Front. Genet. 4:4. doi: 10.3389/fgene.2013.00004.

Le Saux, O., Urban, Z., Tschuch, C., Csiszar, K., Bacchelli, B., Quaglino, D., etal. (2000). Mutations in a gene encoding an $\mathrm{ABC}$ transporter cause pseudoxanthoma elasticum. Nat. Genet. 25, 223-227. doi: 10.1038/76102

Li, Q., Grange, D. K., Armstrong, N. L., Whelan, A. J., Hurley, M. Y., Rishavy, M. A., et al. (2009a). Mutations in the GGCX and ABCC6 genes in a family with pseudoxanthoma elasticumlike phenotypes. J. Invest. Dermatol. 129, 553-563. doi: 10.1038/jid. 2008.271

Li, Q., Schurgers, L. J., Smith, A. C., Tsokos, M., Uitto, J., and Cowen, E. W. (2009b). Co-existent pseudoxanthoma elasticum and vitamin K-dependent coagulation factor deficiency: compound heterozygosity for mutations in the GGCX gene. Am. J. Pathol. 174, 534-540. doi: 10.2353/ajpath.2009.080865

Li, Q., and Uitto, J. (2010). The mineralization phenotype in Abcc6 $(-/-)$ mice is affected by Ggcx gene deficiency and genetic backgrounda model for pseudoxanthoma elasticum. J. Mol. Med. 88, 173-181. doi: 10.1007/s00109-009-0522-8

Longas, M. O., Wisch, P., Lebwohl, M. G., and Fleischmajer, R. (1986). Glycosaminoglycans of skin and urine in pseudoxanthoma elasticum: evidence for chondroitin 6-sulfate alteration. Clin. Chim. Acta 155, 227-236. doi: 10.1016/0009-8981(86)90242-1

Maccari, F., Gheduzzi, D., and Volpi, N. (2003). Anomalous structure of urinary glycosaminoglycans in patients with pseudoxanthoma elasticum. Clin. Chem. 49, 380-388. doi: 10.1373/49.3.380

Martin, L., Chassaing, N., Delaite, D., Esteve, E., Maitre, F., and Le Bert, M. (2007). Histological skin changes in heterozygote carriers of mutations in ABCC6, the gene causing pseudoxanthoma elasticum. J. Eur. Acad. Dermatol. Venereol. 21, 368-373. doi: 10.1111/j.1468-3083.2006.01940.x

Martin, L., Maitre, F., Bonicel, P., Daudon, P., Verny, C., Bonneau, D., et al. (2008). Heterozygosity for a single mutation in the ABCC6 gene may closely mimic PXE: consequences of this phenotype overlap for the definition of PXE. Arch. Dermatol. 144, 301-306. doi: 10.1001/archderm.144.3.301

Miksch, S., Lumsden, A., Guenther, U. P., Foernzler, D., Christen-Zach,
S., Daugherty, C., et al. (2005). Molecular genetics of pseudoxanthoma elasticum: type and frequency of mutations in ABCC6. Hum. Mutat. 26, 235-248. doi: 10.1002/humu. 20206

Munroe, P. B., Olgunturk, R. O., Fryns, J. P., Van Maldergem, L., Ziereisen, F., Yuksel, B., et al. (1999). Mutations in the gene encoding the human matrix Gla protein cause Keutel syndrome. Nat. Genet. 21, 142-144. doi: $10.1038 / 5102$

Neldner, K., and Struk, B. (2002). "Pseudoxanthoma elasticum," in Connective Tissue and Its Heritable Disorders, eds P. M. Royce and B. Steinmann. (New York: Wiley-Liss Inc.), 561-583. doi: 10.1002/047122 1929.ch11

Nitschke, Y., Baujat, G., Botschen, U., Wittkampf, T., Du Moulin, M., Stella, J., et al. (2012). Generalized arterial calcification of infancy and pseudoxanthoma elasticum can be caused by mutations in either ENPP1 or ABCC6. Am. J. Hum. Genet. 90, 25-39. doi: 10.1016/j.ajhg.2011. 11.020

Peloso, G. M., Demissie, S., Collins, D., Mirel, D. B., Gabriel, S. B., Cupples, L. A., et al. (2010). Common genetic variation in multiple metabolic pathways influences susceptibility to low HDL-cholesterol and coronary heart disease. J. Lipid Res. 51, 3524-3532. doi: 10.1194/jlr.P008268

Pfendner, E. G., Vanakker, O. M., Terry, S. F., Vourthis, S., Mcandrew, P. E., Mcclain, M. R., etal. (2007). Mutation detection in the ABCC6 gene and genotype-phenotype analysis in a large international case series affected by pseudoxanthoma elasticum. J. Med. Genet. 44, 621-628. doi: 10.1136/jmg.2007.051094

Pisciotta, L., Tarugi, P., Borrini, C., Bellocchio, A., Fresa, R., Guerra, D., et al. (2010). Pseudoxanthoma elasticum and familial hypercholesterolemia: a deleterious combination of cardiovascular risk factors. Atherosclerosis 210, 173-176. doi: 10.1016/j.atherosclerosis.2009. 11.028

Plomp, A. S., Bergen, A. A., Florijn, R. J., Terry, S. F., Toonstra, J., Van Dijk, M. R., et al. (2009). Pseudoxanthoma elasticum: wide phenotypic variation in homozygotes and no signs in heterozygotes for the c.3775delT mutation in ABCC6. Genet. Med. 11, 852858. doi: 10.1097/GIM.0b013e3181c 00a96

Plomp, A. S., Hu, X., De Jong, P. T., and Bergen, A. A. (2004). Does autosomal dominant pseudoxanthoma elasticum exist? Am. J. Med. Genet. 
A 126A, 403-412. doi: 10.1002/ ajmg.a.20632

Quaglino, D., Sartor, L., Garbisa, S., Boraldi, F., Croce, A., Passi, A., et al. (2005). Dermal fibroblasts from pseudoxanthoma elasticum patients have raised MMP2 degradative potential. Biochim. Biophys. Acta 1741, 42-47. doi: 10.1016/j.bbadis.2004.09.012

Ringpfeil, F., Lebwohl, M. G., Christiano, A. M., and Uitto, J. (2000). Pseudoxanthoma elasticum: mutations in the MRP6 gene encoding a transmembrane ATPbinding cassette $(\mathrm{ABC})$ transporter. Proc. Natl. Acad. Sci. U.S.A. 97, 6001-6006. doi: 10.1073/pnas.1000 41297

Rutsch, F., Ruf, N., Vaingankar, S., Toliat, M. R., Suk, A., Hohne, W. et al. (2003). Mutations in ENPP1 are associated with 'idiopathic' infantile arterial calcification. Nat. Genet. 34, 379-381. doi: 10.1038/ ng1221

Schön, S., Schulz, V., Prante, C., Hendig, D., Szliska, C., Kuhn, J., et al. (2006). Polymorphisms in the xylosyltransferase genes cause higher serum XT-I activity in patients with pseudoxanthoma elasticum (PXE) and are involved in a severe disease course. J. Med. Genet. 43, 745-749.

Schulz, V., Hendig, D., Henjakovic, M., Szliska, C., Kleesiek, K., and
Götting, C. (2006). Mutational analysis of the ABCC6 gene and the proximal ABCC6 gene promoter in German patients with pseudoxanthoma elasticum (PXE). Hum. Mutat. 27,831 .

Stenvinkel, P., Wang, K., Qureshi, A. R., Axelsson, J., Pecoits-Filho, R. Gao, P., et al. (2005). Low fetuin-A levels are associated with cardiovascular death: impact of variations in the gene encoding fetuin. Kidney Int 67, 2383-2392. doi: 10.1111/j.15231755.2005.00345.x

Trip, M. D., Smulders, Y. M., Wegman, J. J., Hu, X., Boer, J. M., Ten Brink, J. B., et al. (2002). Frequent mutation in the ABCC6 gene (R1141X) is associated with a strong increase in the prevalence of coronary artery disease. Circulation 106, 773-775. doi: 10.1161/01.CIR.0000028420. 27813.C0

Vanakker, O. M., Martin, L., Gheduzzi, D., Leroy, B. P., Loeys, B. L., Guerci, V. I., et al. (2007). Pseudoxanthoma elasticum-like phenotype with cutis laxa and multiple coagulation factor deficiency represents a separate genetic entity. J. Invest. Dermatol. 127, 581-587. doi: 10.1038/sj.jid. 5700610

Volpi, N., and Maccari, F. (2005). Composition of urinary glycosaminoglycans in a patient with pseudoxanthoma elasticum and familial mediterranean fever. Clin. Chim.
Acta359, 207-209. doi: 10.1016/ j.cccn.2005.04.008

Wang, J., Near, S., Young, K., Connelly, P. W., and Hegele, R. A. (2001). ABCC6 gene polymorphism associated with variation in plasma lipoproteins. J. Hum. Genet. 46, 699-705. doi: 10.1007/s1003801 70003

Wegman, J. J., Hu, X., Tan, H., Bergen, A. A., Trip, M. D., Kastelein, J. J., et al. (2005). Patients with premature coronary artery disease who carry the ABCC6 R1141X mutation have no pseudoxanthoma elasticum phenotype. Int. J. Cardiol. 100, 389393. doi: 10.1016/j.ijcard.2004.07. 012

Zarbock, R., Hendig, D., Szliska, C., Kleesiek, K., and Götting, C. (2007). Pseudoxanthoma elasticum: genetic variations in antioxidant genes are risk factors for early disease onset. Clin. Chem. 53, 1734 1740.

Zarbock, R., Hendig, D., Szliska, C., Kleesiek, K., and Götting, C. (2009). Vascular endothelial growth factor gene polymorphisms as prognostic markers for ocular manifestations in pseudoxanthoma elasticum. Hum. Mol. Genet. 18, 3344-3351. doi: 10.1093/hmg/ddp259.

Zarbock, R., Hendig, D., Szliska, C., Kleesiek, K., and Götting, C. (2010). Analysis of MMP2 promoter polymorphisms in patients with pseudoxanthoma elasticum. Clin. Chim. Acta 411, 1487-1490. doi: 10.1016/j.cca.2010.06.006

Conflict of Interest Statement: The authors declare that the research was conducted in the absence of any commercial or financial relationships that could be construed as a potential conflict of interest.

Received: 21 December 2012; accepted: 30 May 2013; published online: 19 June 2013.

Citation: Hendig D, Knabbe $C$ and Götting C (2013) New insights into the pathogenesis of pseudoxanthoma elasticum and related soft tissue calcification disorders by identifying genetic interactions and modifiers. Front. Genet. 4:114. doi: 10.3389/fgene.2013. 00114

This article was submitted to Frontiers in Systems Biology, a specialty of Frontiers in Genetics.

Copyright (C) 2013 Hendig, Knabbe and Götting. This is an open-access article distributed under the terms of the Creative Commons Attribution License, which permits use, distribution and reproduction in other forums, provided the original authors and source are credited and subject to any copyright notices concerning any third-party graphics etc. 